Anat. Inst. d. Med. Fak., Univ. Okayama (Vorstand: Prof. M. SEKI).

\title{
Veränderungen der Stärke der Pjs-SCHIFF-Reaktion und der Färbbarkeit mit Resorcinfuchsin der Gewebselemente der Brustaorta der Hühner während der prä- und post- natalen Entwicklung.
}

\author{
家䌖の胸大動脈壁の組織成分の Pjs-Schiff 反応とレゾルチン \\ フクンン染色性の強さの生前と生後の発育中の変化. \\ Kodo KINUKAWA 衣川弘道.
}

(Eingegangen am 7. August 1957.)

\section{Material und Methode.}

Es gibt meines Wissens noch keine systematische Untersuchung über die im Titel erwähnten Veränderungen der Reaktion und Färbbarkeit der Arterienwand.

Es wurde die Brustaorta von 7, 13 und 19 Tage alten Hühnerembryonen und 3 und 7 Tage alten Hühnchen als Material gewählt. Man fixierte die Brustaorta mit dem umgebenden Gewebe in LISONschem Bleiacetat-Formalin 3 Tage lang und bettete sie in Paraffin ein, um Schnitte von $10 \mu$ Dicke zu bekommen. Auf die Polysaccharideverbindungen in der Aortenwand wurde die Perjodsäure-SCHIFF-Reaktion (Pjs-SCHIFF-Reaktion) ausgeführt, und die elastischen Elemente in ihr wurden mit Resorcinfuchsin gefärbt. Die miteinander zu vergleichenden Objekte wurden immer möglichst gleichzeitig in gleicher Weise behandelt.

\section{Ergebnisse der Untersuchung.}

a) Pjs-SCHIFF-Reaktion zur Darstellung der Polysaccharideverbindungen.

Vor allem sei auf die in Abb. $1-5$ erscheinenden dunklen und dunkel umrandeten hellen Körnchen aufmerksam gemacht, welche bei der Fixierung des Gewebes in der Bleiazetat reichlich enthaltenden Fixierungsflüssigkeit niedergeschlagen sind. Sie können durch wiederholte Wasserspülung der Gewebsschnitte nur schwer beseitigt werden.

Am 7tägigen Hühnerembryo tritt die Pjs-SCHIFF-Reaktion an den elastischen Elementen in der Wand der Brustaorta noch nicht besonders stark ein, und die an der Matrixsubstanz kaum (Abb. 1). Am 13. Bruttage vermehrt sich die Stärke der Reaktion an den beiden Bestandteilen ein wenig (Abb. 2), und am 19. Bruttage noch mehr (Abb. 3), ohne daß die elastischen 
Elemente als solche imponieren. Es muß hierbei zugestanden werden, daß in den Schnitten von dem in Paraffin eingebetteten Material die Matrixsubstanz in verschiedensten Formen zur Gerinnung gekommen und also nicht mehr amorph ist. Doch ist ihre reaktive Eigenschaft im großen zu konstatieren. Am 3. und 7. Lebenstage (Abb. 4 und 5) fällt die Reaktion distinkt und sehr stark aus.

Mit der Entwicklung verstärkt sich also die Pjs-SCHIFF-Reaktion an den elastischen Elementen, und zugleich die Reaktion an der Matrixsubstanz. Darauf hat auch SMITH u. a. (1951) bei der Untersuchung an der Aorta der Maus hingewiesen. Nach ihnen tritt die Pjs-SCHIFF-Reaktion beim jungen Tieren weniger stark positiv ein.

b) Färbung mit Resorcinfuchsin zur Darstellung der elastischen Elemente.

Nach dieser Färbung erscheinen die elastischen Elemente in der Wand der Brustaorta am 7. Bruttage schwach blauviolett (Abb. 6), am 13. Bruttage aber etwas stärker (Abb. 7), wobei sie an Zahl und Dicke zunehmen. Am 19. Bruttage wird die Änderung noch viel stärker (Abb. 8). Am 3. und 7. Lebenstage färben sich die elastischen Elemente dunkelblauviolett (Abb. 9). Im Verlauf der Zunahme von Lebenstagen nimmt zwar die Dicke der elastischen Elemente im allgemeinen zu, ihre Zahl aber bleibt anscheinend fast gleich.

\section{Auswertung der Ergebnisse.}

Das starke Ausfallen der Pjs-SCHIFFschen Reaktion an den elastischen Elementen beobachtete man schon lange. WISLOCKI u. a. (1947) haben festgestellt, daß die elastischen Fasern in der Arterienwand des Nabelstranges des menschlichen Föten vom 3. Monate bis zur letzten Periode eine schwache BAUERsche Reaktion auf Polysaccharide geben. Nach SEO (1955) soll am 14tägigen Rattenembryo die Pjs-SCHIFF-Reaktion auf Gefäßen (deren Namen unerwähnt) selbst nach der Speichelbehandlung schwach positiv ausfallen, wobei am 20tägigen die Reaktion auf den elastischen Fasern in der Intima und Media der Aorta abdominalis etwas stärker wird. Nach meiner Untersuchung verstärkt sich die Pjs-SCHIFF-Reaktion auf den elastischen Elementen in der Brustaorta des Hühnerembryos mit der Zunahme der Tagesabläufe, und zugleich nehmen ihre Dicke und Zahl sowie die Stärke der Pjs-SCHIFF Reaktion auf der Matrixsubstanz zu. Die Verstärkung der Färbbarkeit der elastischen Elemente mit Resorcinfuchsin zeigt nach der Meinung von SEKI (1934) eine Vermehrung der gesamten inneren Oberfläche der Elemente und ihrer Ultrastrukturdichte. 


\section{Zusammenfassung.}

Die Perjodsäure-SCHIFF-Reaktion auf Polysaccharide verstärkt sich an den elastischen Elementen sowie an der Matrixsubstanz der Brustaortenwand während der Entwicklung. Zugleich nimmt ihre Färbbarkeit mit Resorcinfuchsin fortwährend zu. Es gibt also alle möglichen Reifezustände der elastischen Elemente, von denen die Jüngeren ultrastrukturell weniger dicht und die Älteren mehr dicht gebaut sind.

\section{内 容自 抄.}

胎生 $7,13,19$ 日 と生後 3 と 7 日の家鶏の胸大動脈壁で標記の反応と染色 性変化が検べられた，発育と共に弾性成分と基質にての多糖類化合物の過 ヨード酸 Schiff 反応が強くなる。また発育と共に次第に弾性成分のレゾル チンフクンンでの染色性が増して，その全内表面が増し，超構密度が高く なり，弾性成分の成熟炕あらゆる段階があることが示された。

\section{Literatur.}

Seki, M.: Zur physikalischen Chemie der histologischen Färbung. VII. Elastikafärbung mit Weigertschen Farbe. Okajimas Fol. 12 (1934). - Seo, S.: Changes in the reaktion of tissues to periodic acid Schiff's stain during the development of white rat. Kyushu Memoirs med. Sci. 5 (1955). - Smith, C., M. M. Seitner a. H. Wang : Aging changes in the tunica media of the aorta. Anat. Rec. 109 (1951). - Wislocki, G. B., H. Bunting a. E. W. Dempsey : Metachromasia in mammalian tissues and its relationship to mucopolysaccharides. Amer. J. Anat. 81 (1947). 


\section{Erläuterung zu den Tafelabbildungen.}

Abb. 1-5. Aus der Wand der Brustaorta. Pjs-SCHIFF-Reaktion. $400 \times$ Abb. 1. Am 7. Bruttage. Pjs-SCHIFF-Reaktion.

Abb. 2. Am 13. Bruttage. Pjs-SCHIFF-Reaktion.

Abb. 3. Am 19. Bruttage. Pjs-SCHIFF-Reaktion. 
K. KINUKAWA (1)
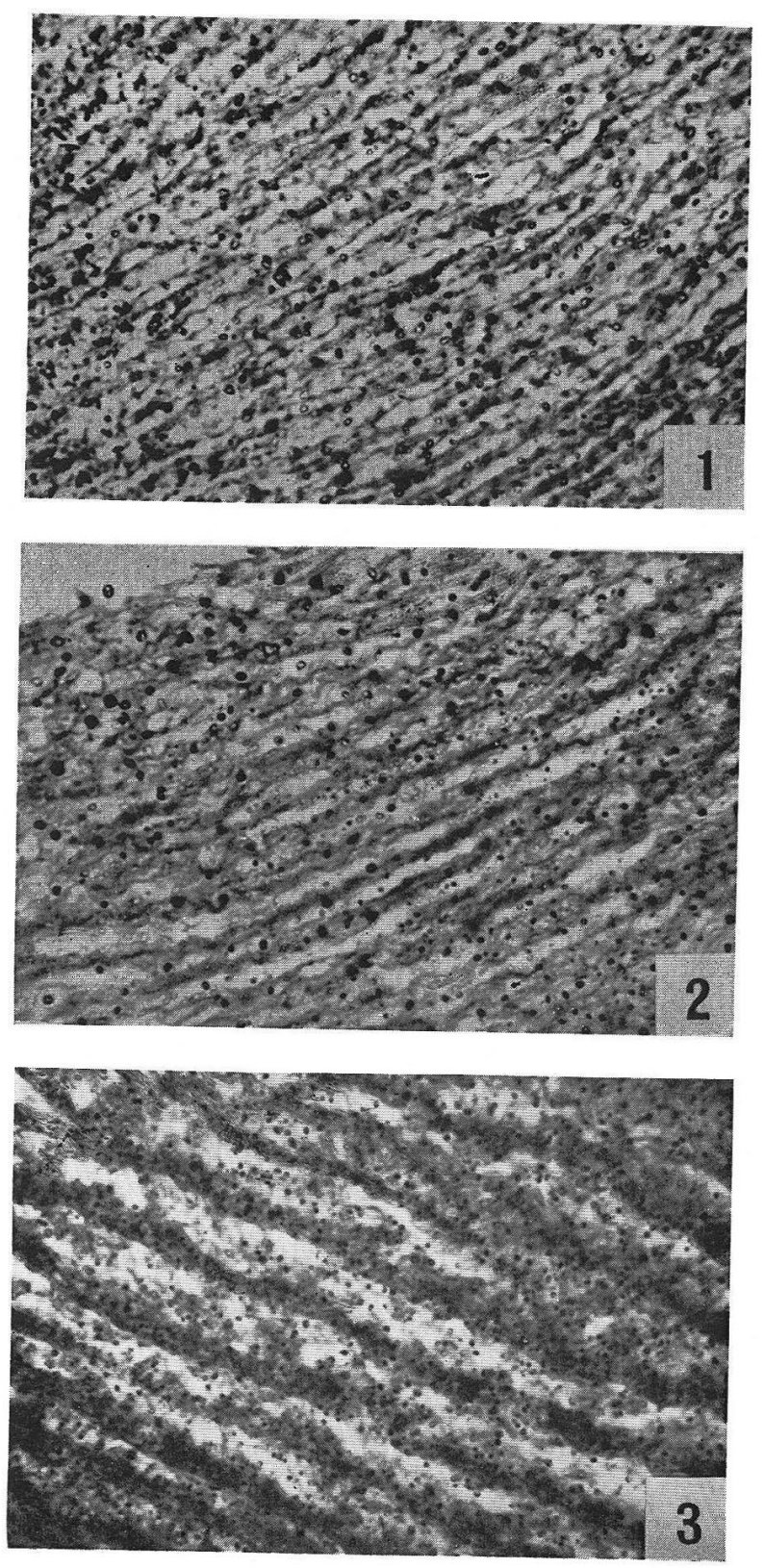
Abb. 4. Am 3. Lebenstage. Pjs-SCHIFF-Reaktion.

Abb. 5. Am 7. Lebenstage. Pjs-SCHIFF-Reaktion. 
K. KINUKAWA (2)
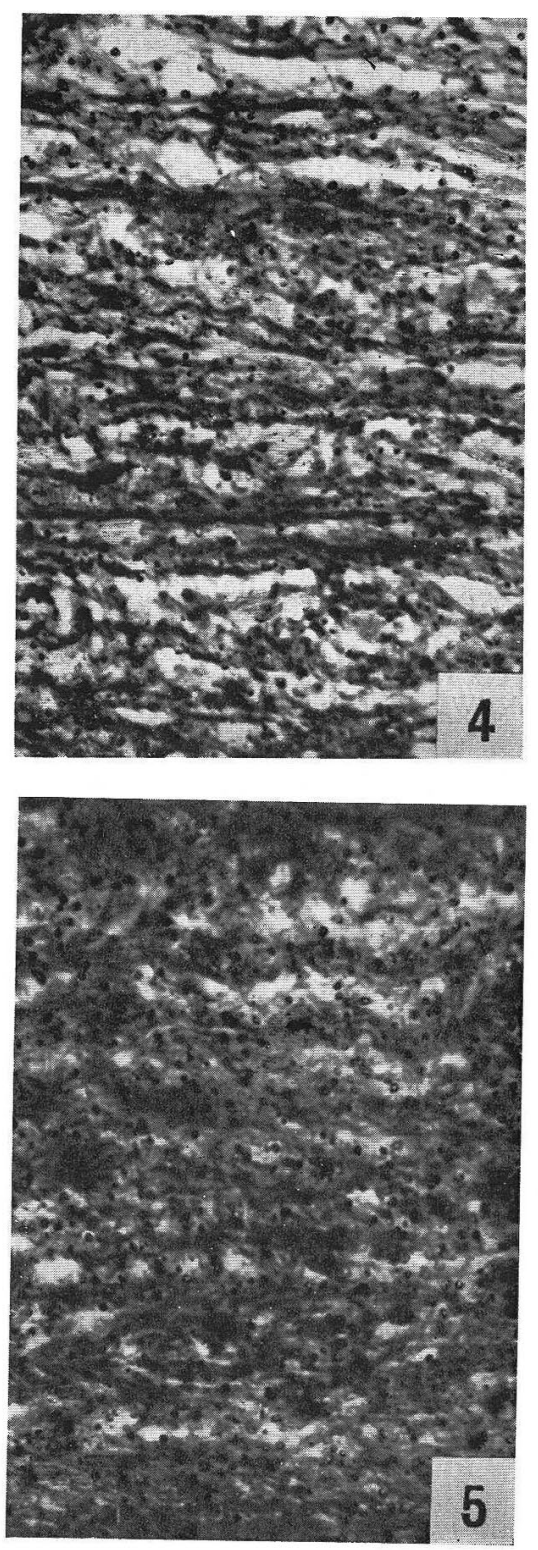
Abb. 6-9. Aus der Wand der Brustaorta. Färbung mit Resorcinfuchsin. $400 \times$ Abb. 6. Am 7. Bruttage. Resorcinfuchsinfärbung.

Abb. 7. Am 13. Bruttage. Resorcinfuchsinfärbung. 


\section{K. KINUKAWA (3)}
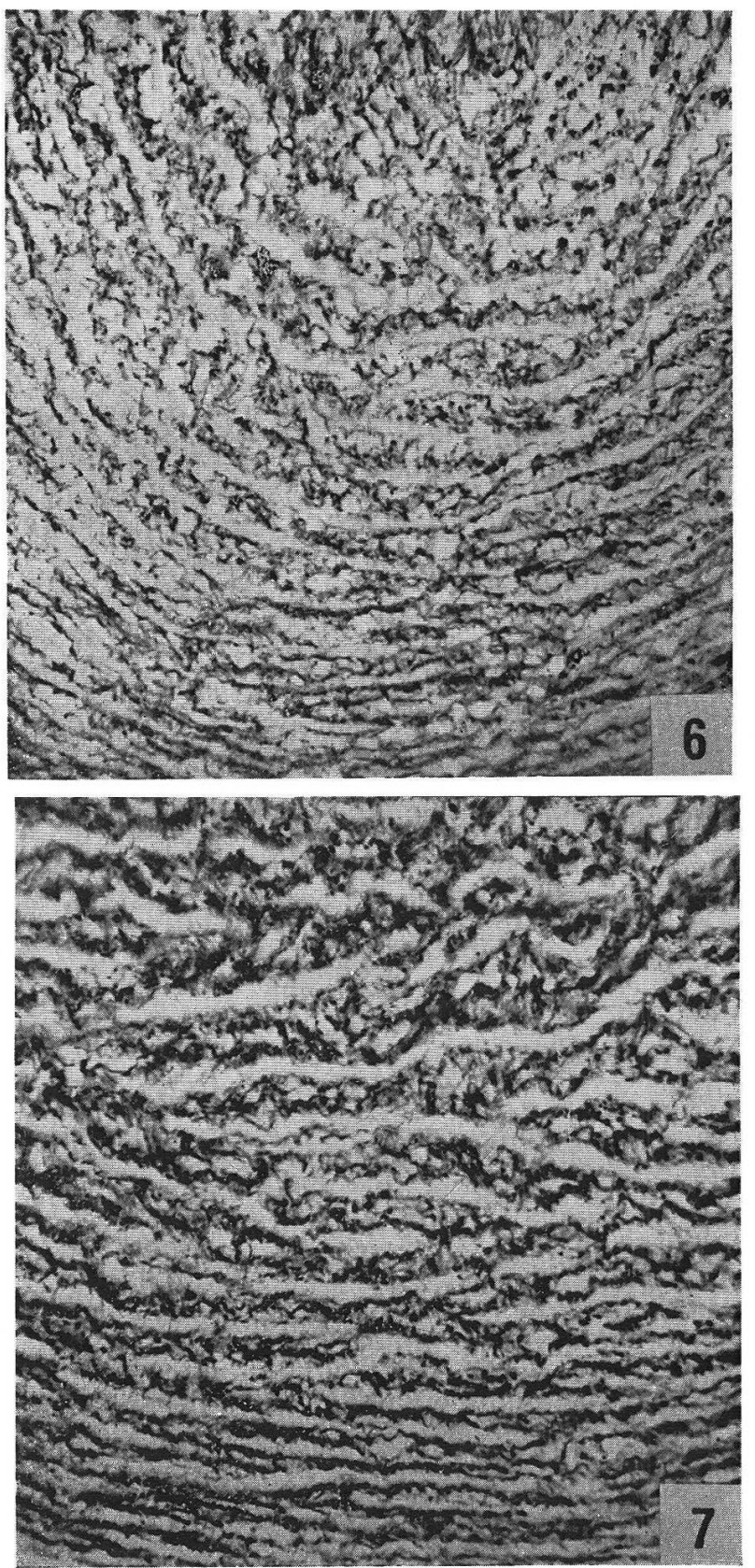
Abb. 8. Am 19. Bruttage. Resorcinfuchsinfärbung.

Abb. 9. Am 7. Lebenstage. Resorcinfuchsinfärbung. 

K. KINUKAWA
(4)
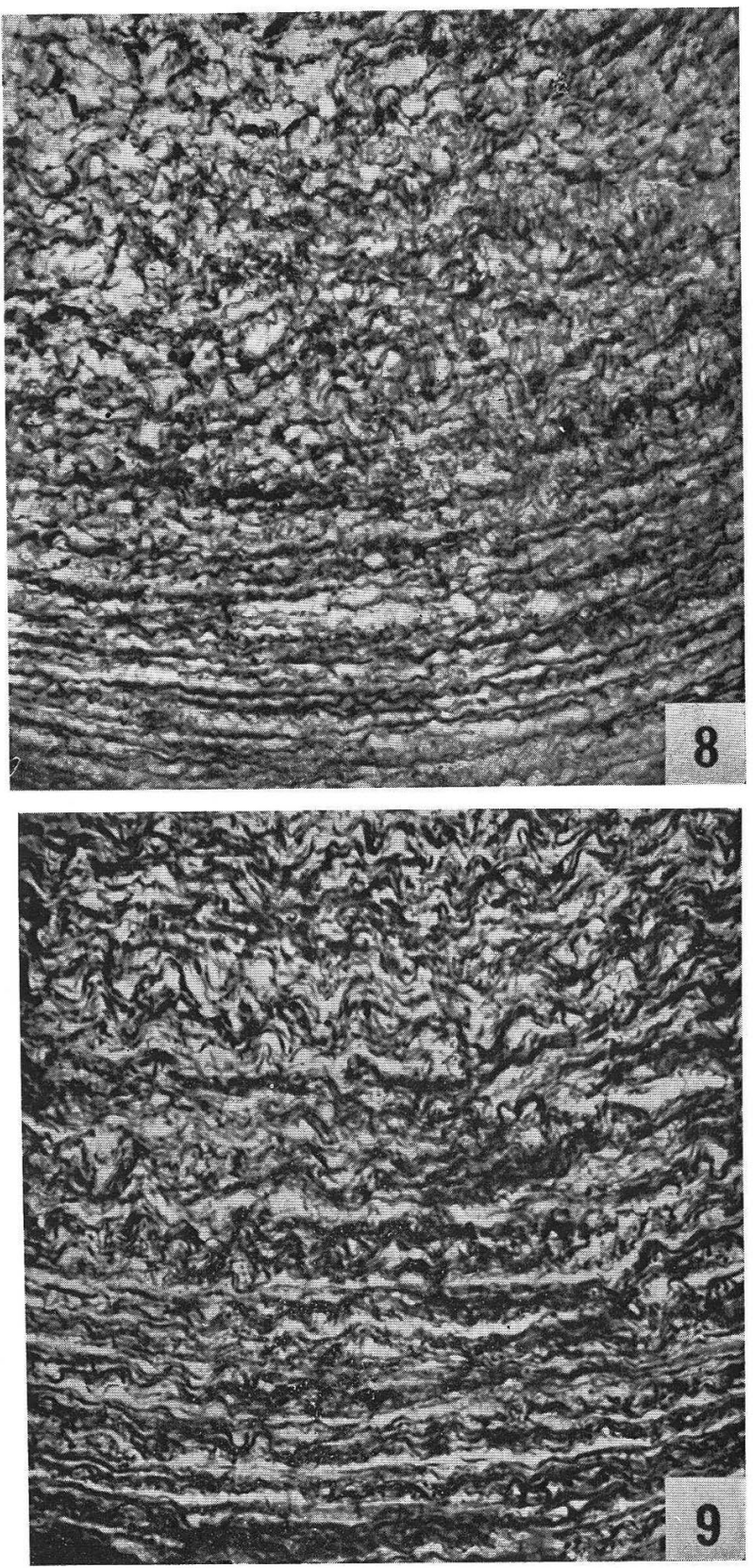